\title{
Biocompatible phosphatidylcholine bilayer coated on magnetic nanoparticles and their application in the extraction of several polycyclic aromatic hydrocarbons from environmental water and milk samples
}

\author{
Shengxiao Zhang a,b , Hongyun Niu ${ }^{\mathrm{a}}$, Yuanyuan Zhang ${ }^{\mathrm{b}}$, Junshen Liu ${ }^{\mathrm{b}}$, Yali Shi ${ }^{\mathrm{a}}$, \\ Xiaole Zhang ${ }^{\mathrm{a}, \mathrm{c}}$, Yaqi Cai ${ }^{\mathrm{a}, *}$ \\ a State Key Laboratory of Environmental Chemistry and Ecotoxicology, Research Center for Eco-Environmental Science, Chinese Academy of Sciences, Beijing 100085, China \\ b School of Chemistry and Materials Science, Ludong University, Yantai 264025, China \\ ${ }^{\mathrm{c}}$ College of Chemical Engineering and Biological Technology, Hebei United University, Tangshan 063000, Hebei, China
}

\section{A R T I C L E I N F O}

\section{Article history:}

Received 29 February 2012

Received in revised form 14 March 2012

Accepted 14 March 2012

Available online 23 March 2012

\section{Keywords:}

Magnetic nanoparticles

Phosphatidylcholine

Solid-phase extraction

Polycyclic aromatic hydrocarbons

\begin{abstract}
A B S T R A C T
In this work, phosphatidylcholine (PC) was coated on magnetic nanoparticles to form lipid bilayer as solid-phase extraction (SPE) sorbents for the enrichment of polycyclic aromatic hydrocarbons (PAHs) from environmental water and milk samples. The lipid bilayer was coated on $\mathrm{Fe}_{3} \mathrm{O}_{4}$ nanoparticles using a modified dry lipid film hydration method. The resulted $\mathrm{Fe}_{3} \mathrm{O}_{4} / \mathrm{PC}$ could be readily isolated from solution with a magnet, and exhibited excellent adsorption performance to organic pollutants. Only $0.1 \mathrm{~g}$ of sorbents was enough to extract PAHs from $500 \mathrm{~mL}$ aqueous solution, and $6 \mathrm{~mL}$ of acetonitrile was required to desorb them. The method was fast and relied on $10 \mathrm{~min}$ extraction time and 5 min magnetic separation. The proposed method was successfully applied to determine PAHs in some environmental water and milk samples. The detection limit was in the range of $0.2-0.6 \mathrm{ng} \mathrm{L}^{-1}$. The recoveries of the spiked water samples ranged from $89 \%$ to $115 \%$ with relative standard deviations (RSD) varying from $1 \%$ to $8 \%$. For spiked milk samples, RSD was satisfactory (1-9\%), but the recoveries were relatively low (42-62\%). We show the potentials of $\mathrm{Fe}_{3} \mathrm{O}_{4} / \mathrm{PC}$ sorbents in environmental water and biological sample analyses.
\end{abstract}

(c) 2012 Elsevier B.V. All rights reserved.

\section{Introduction}

Solid-phase extraction (SPE) is the most commonly used pretreatment and pre-concentration method for the analyses of pollutants in environmental and biological samples. Traditional SPE method involves passing samples completely through cartridges filled with sorbents, and is therefore time consuming and labor intensive, especially for large volume of samples. In order to overcome these disadvantages, a magnetic SPE method has been developed and applied to bioseparation and chemical analyses by many research groups [1-20]. In this method, paramagnetic sorbents are dispersed in solution to adsorb the targets and then collected by a magnet for elution, which greatly simplifies the SPE procedure. Various magnetic sorbents have been successfully synthesized for sample pretreatment. Our groups have developed mixed hemimicelle [1-4] and octadecyl $\left(C_{18}\right)$ [5,6] functionalized magnetic nanoparticles as sorbents for extraction of target

\footnotetext{
* Corresponding author at: Chinese Academy of Sciences, Research Center for EcoEnvironmental Sciences, P.O. Box 2871, Beijing 100085, China. Tel.: +86010 62849239; fax: +8601062849182.

E-mail address: caiyaqi@rcees.ac.cn (Y.Cai).
}

compounds. Magnetic nanoparticles coated with hemimicelles of alkyl carboxylates are used to extract polycyclic aromatic hydrocarbons (PAHs) from environmental water samples, and surfactant-free extracts are obtained due to the strong chemical bonding between alkyl carboxylates and magnetite [16]. Zhang et al. [17] have investigated ionic liquid-coated magnetic $\mathrm{Fe}_{3} \mathrm{O}_{4}$ nanoparticles as an adsorbent of mixed hemimicelles solid-phase extraction for the preconcentration of PAHs from environmental samples. Carbon-ferromagnetic nanocomposite was proposed for the extraction of PAHs in environmental samples [18]. A hydrophobic sublayer and a hydrophilic surface endowed the sorbent high extraction capability and good compatibility with sample matrix, respectively. Shi et al. [20] developed a microextraction technique based on hydrophobic magnetic nanoparticles retrieved the extractant of 1-octanol for the fast determination of PAHs in environmental samples, which combining dispersive liquid-liquid microextraction and dispersive microsolid-phase extraction.

As main components of cellular membrane [21], phospholipids have perfect biocompatibility. Phosphatidylcholine (PC) is a typical and commonly used phospholipid. As shown in Scheme 1(a), PC consists of a long double carbon chain, and the zwitterions pair headgroup is composed of phosphate and choline. Phospholipids have been adsorbed on various matrixes [22-26], 

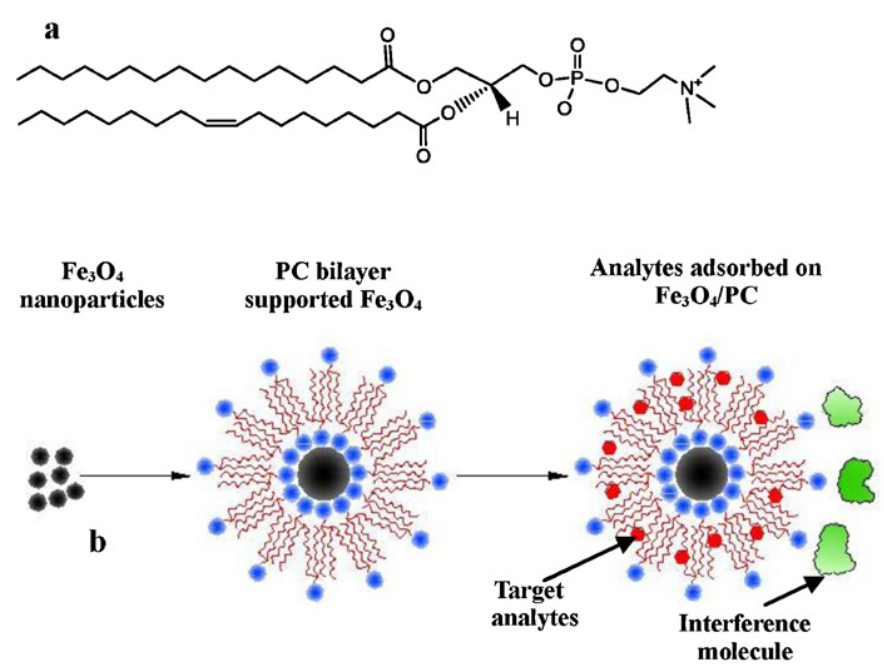

Scheme 1. Diagrams of (a) the chemical structure of PC and (b) supported lipid bilayers on magnetic nanoparticle for target analytes adsorption.

including nanomaterials [27-33], to form supported lipid bilayers. Magnetoliposomes are magnetic nanoparticles coated with lipid bilayer, and have been prepared for medical applications such as targeted drug delivery, hyperthermia, and attachment of antibody molecules [34-37]. Scheme 1(b) shows the supported lipid bilayer structure of phospholipids formed on nanoparticle substrate. Firstly, the hydrophilic zwitterions headgroups are adsorbed on the surface of substrate, and the adsorption has two driving forces-entropy increase due to displacement of water molecules around nanoparticles by the phospholipid molecules and charge-dipole attraction between the charged nanoparticles and the phosphor-nitrogen dipole of the phospholipid headgroups [33]. With more and more phospholipids adsorbed onto the substrate, the surface saturates, and then the hydrophobic interactions between tails of hydrocarbon chains result in the formation of bilayers. As shown in Scheme 1(b), the formation of the supported lipid bilayers endows the substrate with good characteristics. First, the middle hydrocarbon chains provide adsorption sites for organic pollutants due to hydrophobic interactions. Second, the zwitterions pair headgroups endow the outer surface of the substrate with perfect hydrophilicity and biocompatible. Thus, when coated with PC bilayer membranes, the novel magnetic SPE sorbent is expected to have natural resistance to protein fouling and other interference.

With the excellent adsorption ability, the supported lipid bilayers have great potential in analytical chemistry. Few studies have been reported on the application of supported lipid bilayers for analytical chemistry. Phillips et al. [26] have tested zwitterionic PC-, cationic ethylphosphocholine-, and anionic phosphatidylglycerolsupported bilayer on poly(dimethylsiloxane)/glass hybrid microchips to electrophoretically separate biomedically significant analytes. Castellana et al. [38] have developed lipid-capped gold nanorod as a label-free mass spectrometry and optical detectionbased biosensor for the detection of a lipophilic drug in aqueous solution and a lipopeptide in serum. In present, there are no reports about lipid bilayer supported on nanoparticles as sorbents for extraction or adsorption of pollutants.

In this study, a modified dry-lipid film hydration method was applied to prepare magnetic $\mathrm{Fe}_{3} \mathrm{O}_{4}$ nanoparticles coated with PC bilayer membrane $\left(\mathrm{Fe}_{3} \mathrm{O}_{4} / \mathrm{PC}\right)$, which was then used as magnetic sorbents to extract pollutants from some environmental water and milk samples. To examine the feasibility of this method, six cancerigenic PAHs were selected as target compounds, which were distributed widespread in the environment, many of them showing carcinogenic effects. We investigated effect of extraction conditions on analytes recoveries, such as amount of sorbents, volume of desorption solution, extraction time, humic acid, and protein. After extraction, the analytes in eluent were detected using high performance liquid chromatography (HPLC) equipped with fluorescence detector (FLD). Using this novel SPE technique, we analyzed some water samples, a milk sample, and their spiked samples.

\section{Materials and methods}

\subsection{Chemicals and materials}

All reagents used in the experiments were of analytical reagent grade and used without further purification. Fluoranthene (FluA), pyrene (Pyr), benz[a]anthracene (BaA), benzo[b]fluoranthene (BbF), benzo[a]pyrene (BaP), and benzo[g,h,i]perylene (BghiP) were obtained from AccuStandard (New Haven, USA). Phosphatidylcholine from soybean and bovine serum albumin (BSA) were supplied by Sigma-Aldrich (Steinheim, Germany). Ferric chloride $\left(\mathrm{FeCl}_{3} \cdot 4 \mathrm{H}_{2} \mathrm{O}\right)$ and ferrous chloride $\left(\mathrm{FeCl}_{2} \cdot 6 \mathrm{H}_{2} \mathrm{O}\right)$ were purchased from Beijing Chemical Corporation (Beijing, China). HPLC-grade acetonitrile were obtained from Fisher Scientific Corporation (Fair Lawn, NJ, USA). Ultrapure water was prepared using Milli-Q water purification system (Bedford, MA, USA).

\subsection{Preparation of $\mathrm{Fe}_{3} \mathrm{O}_{4}$ and $\mathrm{Fe}_{3} \mathrm{O}_{4} / \mathrm{PC}$}

$\mathrm{Fe}_{3} \mathrm{O}_{4}$ nanoparticles were prepared by chemical coprecipitation [39]. $\mathrm{FeCl}_{2} \cdot 4 \mathrm{H}_{2} \mathrm{O}(2 \mathrm{~g}), \mathrm{FeCl}_{3} \cdot 6 \mathrm{H}_{2} \mathrm{O}(5.2 \mathrm{~g})$ and $0.85 \mathrm{~mL}$ concentrated hydrochloric acid were dissolved into $25 \mathrm{~mL}$ of deionized water. The resulting solution was added in drops into $250 \mathrm{~mL}$ of $1.5 \mathrm{M} \mathrm{NaOH}$ solution under vigorous stirring and nitrogen protection at $353 \mathrm{~K}$. After the reaction, the obtained precipitate was separated from solution by a powerful $\mathrm{Nd}-\mathrm{Fe}-\mathrm{B}$ magnet, washed with deionized water for three times, and then redispersed into $110 \mathrm{~mL}$ deionized water. The concentration of the generated nanoparticles suspension was about $20 \mathrm{mg} \mathrm{mL}^{-1}$.

The $\mathrm{Fe}_{3} \mathrm{O}_{4} / \mathrm{PC}$ nanoparticles were prepared using a modified dry lipid film hydration method [34,36,37]. One gram of $\mathrm{Fe}_{3} \mathrm{O}_{4}$ nanoparticles were rinsed with ethanol $(20 \mathrm{~mL}$ each time) and toluene ( $20 \mathrm{~mL}$ each time) for three times to remove water, dispersed into $30 \mathrm{~mL}$ toluene, and then $0.4 \mathrm{~g}$ of PC was added. The resulted solution was sonicated for $5 \mathrm{~min}$ and evaporated in a rotary evaporator at $313 \mathrm{~K}$ to a thin film. After the mixture was evaporated to dryness, the vessel was placed under vacuum overnight to remove residual solvent. Then the resulted dry film was dispersed into de-ionized water with sonication and hydrated for $12 \mathrm{~h}$. The products were separated from solution with an $\mathrm{Nd}-\mathrm{Fe}-\mathrm{B}$ magnet, washed with methanol ( $20 \mathrm{~mL}$ each time) and de-ionized water (100 mL each time) for three times, respectively, and then dispersed into $70 \mathrm{~mL}$ de-ionized water and stored in refrigerator at $277 \mathrm{~K}$. After dried by freeze drying, the resulted sorbents weighed about $1.4 \mathrm{~g}$, so the concentration of the suspension was about $20 \mathrm{mg} \mathrm{mL}^{-1}$.

\subsection{Characterization of sorbents}

The morphology and particle size of the sorbents were studied using a transmission electron microscope (TEM) (H-7500, Hitachi, Japan) operated at an $80-\mathrm{kV}$ accelerated voltage. The X-ray diffraction (XRD) pattern was collected using a PANalytical X'pert Pro diffractometer. Magnetic property was analyzed using a vibrating sample magnetometer (VSM, LDJ9600). Fourier transform infrared (FT-IR) spectra were taken in $\mathrm{KBr}$ pressed pellets on a NEXUS 670 FT-IR Spectrometer (Madison, WI, USA). 


\subsection{Magnetic SPE procedure}

To prepare water samples, $0.1 \mathrm{~g}$ of $\mathrm{Fe}_{3} \mathrm{O}_{4} / \mathrm{PC}$ sorbents was dispersed into $500 \mathrm{~mL}$ filtered solution, and the solution was stirred with a glass stick for about $20 \mathrm{~s}$ to make the sorbents dispersed adequately. After the mixture was stood for $10 \mathrm{~min}$, an $\mathrm{Nd}-\mathrm{Fe}-\mathrm{B}$ strong magnet was deposited at the bottom of the beaker to separate the sorbents from the solution. It took about $5 \mathrm{~min}$ for the sorbents to separate completely, and the supernatant was decanted. Finally, the analytes were eluted with $6 \mathrm{~mL}$ of acetonitrile. The eluate was concentrated to less than $0.2 \mathrm{~mL}$ with a stream of nitrogen at $323 \mathrm{~K}$ and matched to $1 \mathrm{~mL}$ with acetonitrile. A total of $20 \mu \mathrm{L}$ of this solution was injected into the HPLC system for analysis. To prepare milk sample, $5 \mathrm{~mL}$ of sample was diluted to $500 \mathrm{~mL}$ with de-ionized water to decrease the concentration of protein, and then the same procedures were followed.

\subsection{HPLC-FLD analysis}

PAHs were separated and quantified using an Dionex HPLC system (Sunnyvale, CA, USA). The HPLC equipment included a Dionex P680 HPLC pump, a thermostat column compartment TCC-100, and a Dionex RF 2000 fluorescence detector. A Diamonsil ${ }^{\circledR} C_{18}$ column $(250 \mathrm{~mm} \times 4.6 \mathrm{~mm}$; particle size $5 \mu \mathrm{m})$ was used as the separation column. Gradient separation for PAHs was carried out using water-acetonitrile (50:50) and acetonitrile as A and B solvents, respectively, and the flow rate was $1 \mathrm{~mL} \mathrm{~min}^{-1}$. The linear gradient profile was as follows: A was maintained at $20 \%$ in the first $15 \mathrm{~min}$; linear gradient was performed to $0 \% \mathrm{~A}$ in two min and kept for $3 \mathrm{~min}$; after that, the mobile phase was returned to initial condition in $2 \mathrm{~min}$. PAHs were determined using a fluorescence detector, and the parameters for the time-programmed scan with different excitation/emission wavelengths were as follows: $0 \mathrm{~min}$ at $252 / 370 \mathrm{~nm}, 7 \mathrm{~min}$ at $280 / 460 \mathrm{~nm}, 8 \mathrm{~min}$ at $270 / 390 \mathrm{~nm}, 11 \mathrm{~min}$ at $260 / 432 \mathrm{~nm}, 13.5 \mathrm{~min}$ at $290 / 410 \mathrm{~nm}$, and $22 \mathrm{~min}$ at 252/370 nm.

\subsection{Sample collection}

Tap water sample was taken from our lab in Haidian District (Beijing), and river water sample was acquired from Xiaoqing river (Haidian District, Beijing). Seawater sample was collected from coastal waters in the Bohai Sea (Yantai, Shandong Province). All water samples were collected randomly in glass bottle and filtered through $0.45-\mu \mathrm{m}$ membranes to remove suspended particles. The filtered water samples were stored in glass bottle at room temperature and analyzed within $24 \mathrm{~h}$. Milk sample was produced by Sanyuan Food Co., Ltd. (Beijing) and kept in refrigerator before analysis.

\section{Results and discussion}

\subsection{Characteristics of sorbents}

\subsubsection{Particle size and morphology}

Fig. 1(a) shows the TEM image of $\mathrm{Fe}_{3} \mathrm{O}_{4}$ nanoparticles. The assynthesized $\mathrm{Fe}_{3} \mathrm{O}_{4}$ nanoparticles were irregular in shape like sand with an average diameter of about $10 \mathrm{~nm}$, and they tended to aggregate to larger particles. After coated with PC bilayer (Fig. 1(b and c)), the $\mathrm{Fe}_{3} \mathrm{O}_{4} / \mathrm{PC}$ nanoparticles formed stable $40-60$-nm agglomerates. Similar phenomenon has been observed during the formation of DMPC-supported lipid bilayers on $5-\mathrm{nm} \mathrm{SiO}_{2}$ nanobeads, in which 150-1000-nm agglomerates are formed instead of bilayer around single nanoparticle [27]. In our experiment, the $\mathrm{Fe}_{3} \mathrm{O}_{4} / \mathrm{PC}$ nanoparticles are well monodispersed (Fig. 1(b)) due to their large particle size and biocompatibility with PC bilayers. In addition, the PC bilayer shell was observed as a light area surrounding the dark core

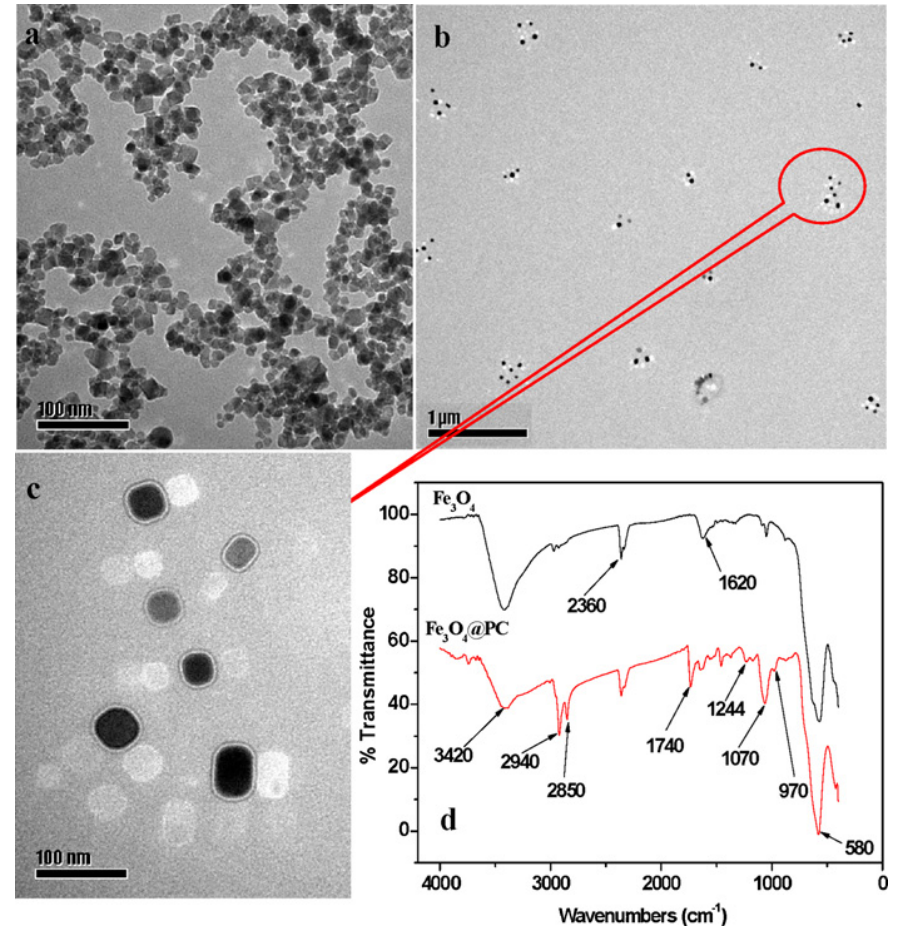

Fig. 1. TEM images of (a) $\mathrm{Fe}_{3} \mathrm{O}_{4}$, (b and c) $\mathrm{Fe}_{3} \mathrm{O}_{4} / \mathrm{PC}$ nanoparticle, and their IR spectra (d). Magnification factor: 200,000 for (a) and (c), 20,000 for (b).

of $\mathrm{Fe}_{3} \mathrm{O}_{4}$ (Fig. 1(c)). The thickness of the PC bilayer shell was around $5 \mathrm{~nm}$, which is close to the thickness of the PC bilayer formed on $\mathrm{SiO}_{2}$ nanobeads [27].

\subsubsection{FT-IR spectra}

FT-IR spectra were acquired for $\mathrm{Fe}_{3} \mathrm{O}_{4}$ and $\mathrm{Fe}_{3} \mathrm{O}_{4} / \mathrm{PC}$ nanoparticles between 4000 and $400 \mathrm{~cm}^{-1}$. Peaks at 3420, 2360,1630, and $580 \mathrm{~cm}^{-1}$ were observed for both $\mathrm{Fe}_{3} \mathrm{O}_{4}$ and $\mathrm{Fe}_{3} \mathrm{O}_{4} / \mathrm{PC}$ nanoparticles (Fig. 1(d)). The peak at $580 \mathrm{~cm}^{-1}$ was ascribed to the characteristic band of $\mathrm{Fe}_{3} \mathrm{O}_{4}$ [14], and the adsorbed water was featured by the bands at 3420 and $1620-1630 \mathrm{~cm}^{-1}$, which were assigned to $\mathrm{O}-\mathrm{H}$ stretching and $\mathrm{H}-\mathrm{O}-\mathrm{H}$ bending modes of vibration [40]. The peaks near $2360 \mathrm{~cm}^{-1}$ might be due to the environmental $\mathrm{CO}_{2}$ molecules. The spectra of $\mathrm{Fe}_{3} \mathrm{O}_{4} / \mathrm{PC}$ consisted of bands at 2940 and $2850 \mathrm{~cm}^{-1}$, which were attributed to symmetric and asymmetric methylene $\left(-\mathrm{CH}_{2}-\right)$ and methyl $\left(-\mathrm{CH}_{3}\right)$ vibrations. The peaks at 1070 and $1244 \mathrm{~cm}^{-1}$ were resulted from vibrational modes of $\mathrm{PO}_{2}{ }^{-}$ headgroups $[28,36]$. Carbonyl $(\mathrm{C}=\mathrm{O})$ vibrations around $1740 \mathrm{~cm}^{-1}$ and quaternary ammonium $\left(\mathrm{CN}^{+}-\left(\mathrm{CH}_{3}\right)_{3}\right)$ asymmetric vibrations at $970 \mathrm{~cm}^{-1}$ were observed for $\mathrm{Fe}_{3} \mathrm{O}_{4} / \mathrm{PC}$ [31]. All the characteristic absorption peaks of PC in the spectra indicated that PC was successfully attached to the surface of $\mathrm{Fe}_{3} \mathrm{O}_{4}$ nanoparticles. The zwitterions pair headgroups of PC endowed the outer surface of $\mathrm{Fe}_{3} \mathrm{O}_{4} / \mathrm{PC}$ with good hydrophilicity and biocompatibility, which ensured the well dispersal of sorbents in solution. The long double hydrocarbon chains provided adsorption sites for organic analytes through hydrophobic interactions.

\subsubsection{Magnetic properties}

It is important for magnetic materials to possess sufficient magnetic properties for separation from solution with external magnetic field. Fig. 2(a) shows the VSM magnetization curves of $\mathrm{Fe}_{3} \mathrm{O}_{4}$ and $\mathrm{Fe}_{3} \mathrm{O}_{4} / \mathrm{PC}$ at room temperature. Both $\mathrm{Fe}_{3} \mathrm{O}_{4}$ and $\mathrm{Fe}_{3} \mathrm{O}_{4} / \mathrm{PC}$ exhibited typical superparamagnetic behavior due to the lack of hysteresis. The remanence and coercivity were nearly zero, illustrating that the particles responded magnetically to an external 

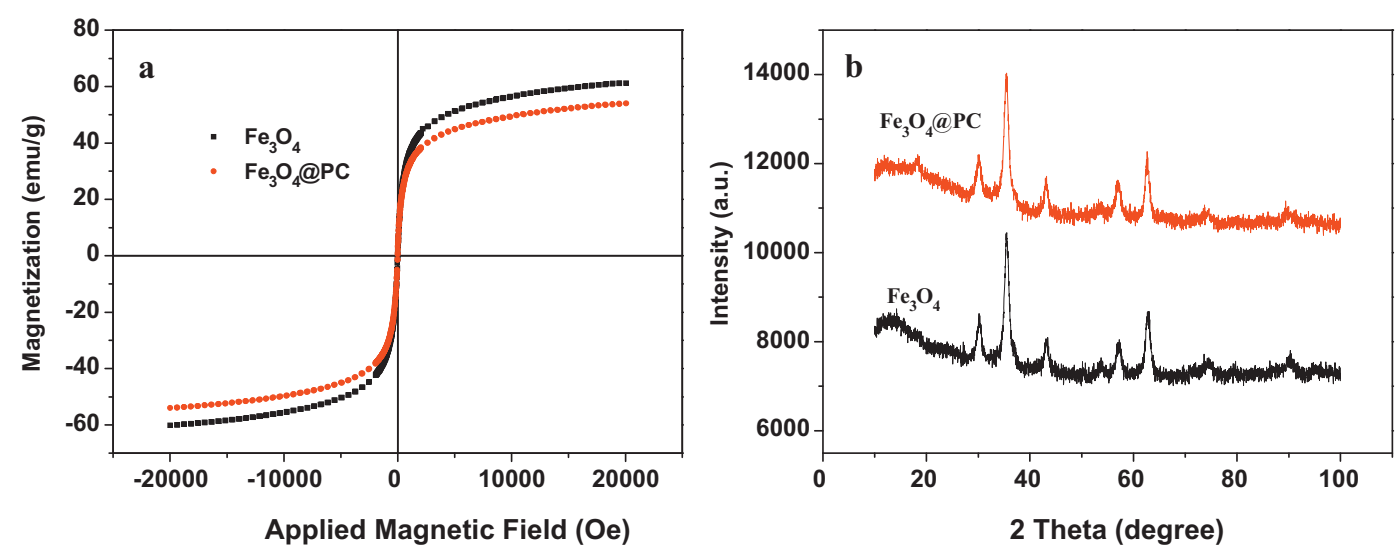

Fig. 2. VSM magnetization curves (a) and X-ray diffraction patterns (b) of $\mathrm{Fe}_{3} \mathrm{O}_{4}$ and $\mathrm{Fe}_{3} \mathrm{O}_{4} / P C$ nanoparticles.

magnetic field and redispersed rapidly when the magnetic field was removed. Another key parameter was the large saturation magnetization, which was a measure of the maximum magnetic strength. The maximal saturation magnetizations of $\mathrm{Fe}_{3} \mathrm{O}_{4}$ and $\mathrm{Fe}_{3} \mathrm{O}_{4} / \mathrm{PC}$ nanoparticles were 60.65 and $54.02 \mathrm{emug}^{-1}$, respectively. The decrease of maximal saturation magnetizations of $\mathrm{Fe}_{3} \mathrm{O}_{4} / \mathrm{PC}$ were likely resulted from the nonmagnetic PC shell. $\mathrm{Fe}_{3} \mathrm{O}_{4} / \mathrm{PC}$ could be easily separated from solution with a powerful $\mathrm{Nd}-\mathrm{Fe}-\mathrm{B}$ magnet because of the superparamagnetism and large saturation magnetization value.

\subsubsection{XRD analysis}

The crystal phase of $\mathrm{Fe}_{3} \mathrm{O}_{4}$ and $\mathrm{Fe}_{3} \mathrm{O}_{4} / \mathrm{PC}$ were investigated by XRD. No obvious difference was observed between the XRD spectra of $\mathrm{Fe}_{3} \mathrm{O}_{4}$ and $\mathrm{Fe}_{3} \mathrm{O}_{4} / \mathrm{PC}$ (Fig. 2(b)). And the pattern matched well with that of cubic crystalline magnetite. This result indicated that the crystal phase of $\mathrm{Fe}_{3} \mathrm{O}_{4}$ nanoparticle was not changed during the coating process.

\subsection{Optimization of extraction conditions}

\subsubsection{Effect of amount of sorbents}

To obtain satisfactory recovery of target compounds, various amount of $\mathrm{Fe}_{3} \mathrm{O}_{4} / \mathrm{PC}(0-100 \mathrm{mg})$ sorbent was tested (Fig. 3(a)). When the amount of sorbents increased, the recovery of all analytes increased sharply in the initial stage, and reached a platform in the later stage. To achieve maximal recovery, only $60 \mathrm{mg}$ of sorbents were enough for $\mathrm{BaA}, \mathrm{BbF}, \mathrm{BaP}$, and BghiP, but $80 \mathrm{mg}$ of sorbents were required for FluA and Pyr. Because the former had stronger hydrophobic properties and easier to be adsorbed than the latter. To assure complete adsorption of analytes, $100 \mathrm{mg}$ of sorbents were used in the following experiment. Compared to traditional SPE catridges that consist of about $0.4-0.9 \mathrm{~g}$ of sorbents [41-45], nanoparticle sorbents have higher surface areas and stronger adsorption ability. Therefore, satisfactory results can be achieved with fewer amounts of sorbents.

\subsubsection{Desorption conditions}

Organic pollutants were easily dissolved in organic solvents. Because of its polarity and intersolubility with water, acetonitrile was selected as desorption solution. After different dosage of acetonitrile was added in the vessel, the mixture was sonicated for $20 \mathrm{~s}$ to desorb analytes adequately. The desorption results are shown in Fig. 3(b). Only $2 \mathrm{~mL}$ of acetonitrile was enough to desorb most of the analytes, and the recoveries of all analytes were over $70 \%$. The recoveries of all analytes increased gradually with increasing dosage of acetonitrile at the beginning, and the recoveries of all analytes were over $80 \%$ when $5 \mathrm{~mL}$ of acetonitrile was used. But the addition of more acetonitrile failed to further improve the recovery. To test effect of sonication time on analytes recoveries, volume of acetonitrile was kept at $2 \mathrm{~mL}$, and sonication time was varied from 10 to 120 s. The results in Fig. 3(c) showed that analytes recoveries enhanced with sonication time increasing from 10 to $20 \mathrm{~s}$, and the recoveries kept constant almost until sonication time reached $60 \mathrm{~s}$. Further prolonging sonication time would lead to a slight decrease for recoveries. From the results we concluded 20-60 s sonication time was appropriate for analytes desorption. The rapid desorption might owe to short diffusion route from nanoscaled sorbents to desorption solution, and the analytes reached partition equilibrium between sorbents and solution. Acetonitrile, the desorption solvent, is easily volatilized, so when sonication time was over $60 \mathrm{~s}$, the slight decrease of analytes recoveries resulted from the loss of desorption solution. Thus, $6 \mathrm{~mL}$ of acetonitrile and $20 \mathrm{~s}$ of sonication time were recommended as eluent to assure complete desorption of the analytes.

\subsubsection{Effect of extraction time}

Sufficient contact time is required for sorbent to achieve adsorption equilibrium. In this study, most of the targets were extracted even when the standing time was $0 \mathrm{~min}$. The recovery of analytes achieved maximum when the standing time increased to $10 \mathrm{~min}$, and there was no obvious change in recovery with prolonged contact time (Fig. 3(d)). A slight decrease of recovery was observed with a standing time of $90 \mathrm{~min}$, which might attributed to the elution difficulty of the analytes due to intraparticle diffusion. Therefore, $10 \mathrm{~min}$ of standing time was used in the following experiment. The $\mathrm{Fe}_{3} \mathrm{O}_{4} / \mathrm{PC}$ nanoparticle sorbent could be isolated from the solution in a short time (within $5 \mathrm{~min}$ ) using a strong $\mathrm{Nd}-\mathrm{Fe}-\mathrm{B}$ magnet. The entire extraction procedure can be finished within $15 \mathrm{~min}$, which meets the requirement of rapid extraction. In contrast, at least $3 \mathrm{~h}$ is needed in traditional SPE method.

\subsubsection{Effect of solution volume}

The effect of solution volume was examined by extracting target compounds with a constant mass of $25 \mathrm{ng}$ from different volumes (50-1500 mL) of aqueous solution. As shown in Fig. 3(e), the recoveries of all analytes decreased gradually with an increasing volume of aqueous solution, but were still over $80 \%$ until the volume of aqueous solution reached $800 \mathrm{~mL}$. When the volume of aqueous solution reached $1500 \mathrm{~mL}$, the recoveries of FluA and Pyr were in the range of $60-70 \%$, while those of other analytes were still over $80 \%$. To assure adequate extraction of all analytes, $500 \mathrm{~mL}$ sample were selected in the real water sample analysis. After enriching the analytes from $500 \mathrm{~mL}$ aqueous solution and condensing the desorption solution to $1 \mathrm{~mL}$, the pre-concentration factors for PAHs were about 500 . 

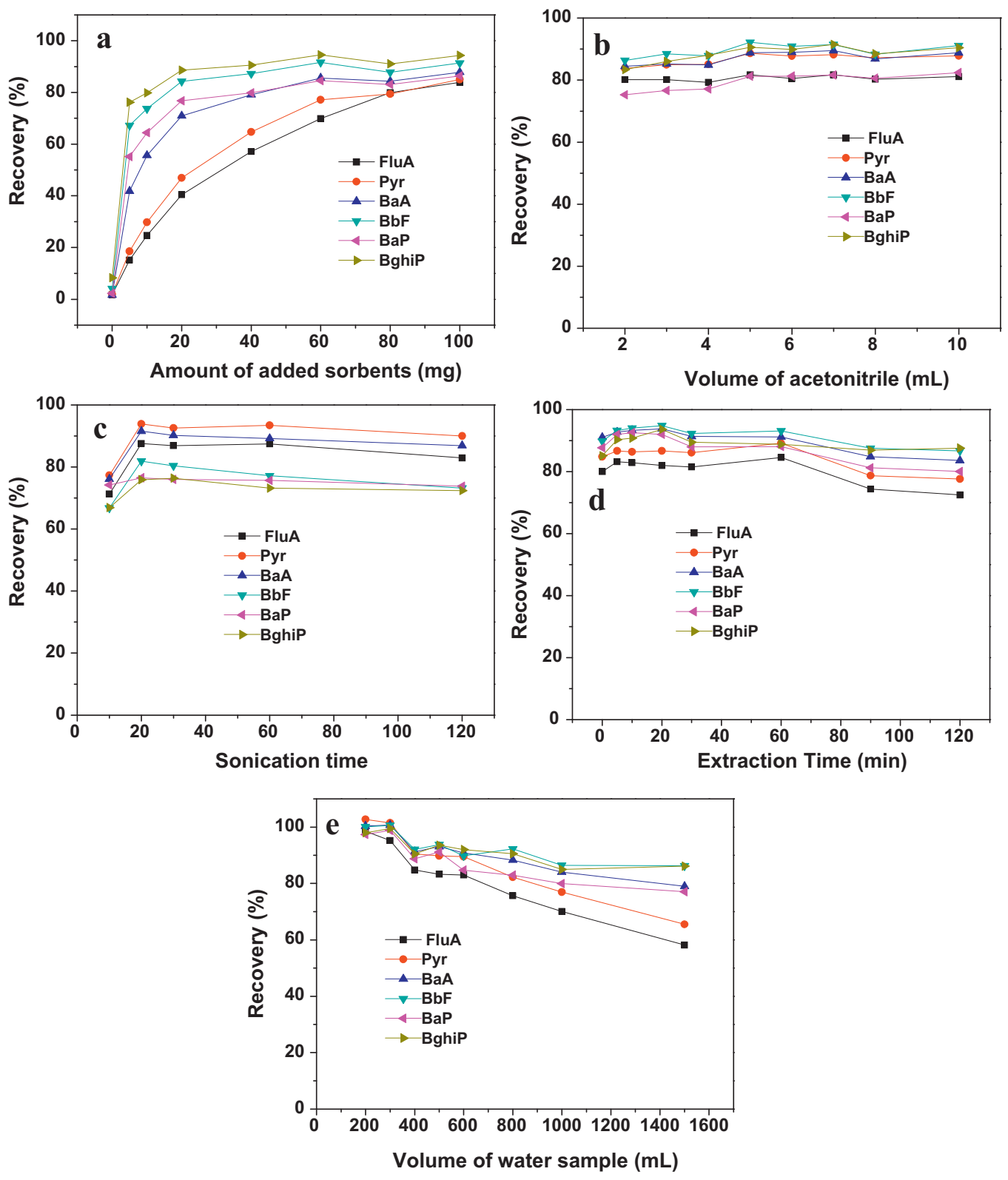

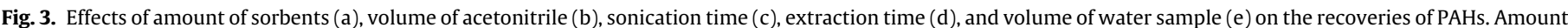

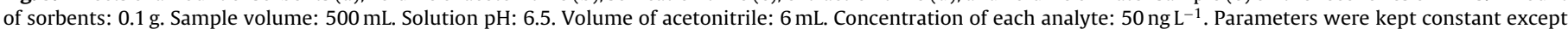
the tested one.

\subsubsection{Interference of humic acid and protein on extraction}

Natural organic matter (NOM) and protein are the most common substances that interfere with the determination of target compounds in environmental water and biological samples. To investigate the effect of NOM on extraction efficiency, humic acid (0-20 $\left.\mathrm{mg} \mathrm{L}^{-1}\right)$ was dispersed in aqueous solution before extraction. The recoveries of all analytes decreased gradually with an increasing concentration of humic acid increasing from 0 to $20 \mathrm{mg} \mathrm{L}^{-1}$ (Fig. 4(a)). When the concentration of humic acid was $5 \mathrm{mg} \mathrm{L}^{-1}$, the recovery of PAHs was still over $70 \%$ except for BghiP (about $60 \%)$. The negative effect might result from the association of PAHs with humic acid $[42,43]$. In traditional SPE method, similar negative effects of humic acid has also been discovered when $\mathrm{C}_{8}$ or $\mathrm{C}_{18}$ silica are used to extract PAHs and other nonpolar compounds [42-45]. The concentration of humic acid generally ranges from 1 to $5 \mathrm{mg} \mathrm{L}^{-1}$ in most surface water samples $[43,44]$. In this range, the recovery of PAHs meets the requirement of analysis.
BSA was selected to examine the effect of protein on extraction of target compounds. As shown in Fig. 4(b), the recoveries of all analytes decreased with the increase of BSA content, but even though the content of BSA was up to $2000 \mathrm{mg} \mathrm{L}^{-1}$, the recoveries of most PAHs were higher than $80 \%$ (the recovery of FluA was about $70 \%$ ). To extract target compounds from biological sample with high concentration of protein, dilution with de-ionized water is necessary to reduce the interference of protein.

\subsection{Analytical performance}

By enriching PAHs from $500 \mathrm{~mL}$ of spiked de-ionized water, calibration curves were established in the range of $1-200 \mathrm{ng} \mathrm{L}^{-1}$. Table 1 lists quantitative parameters of the proposed SPE method, including linear range, correlation coefficient, and detection limit Calibration curves of all analytes exhibited good linearity with a correlation coefficient $(R)$ above 0.999 in the studied range. The detection limits, which were calculated from blank determinations 

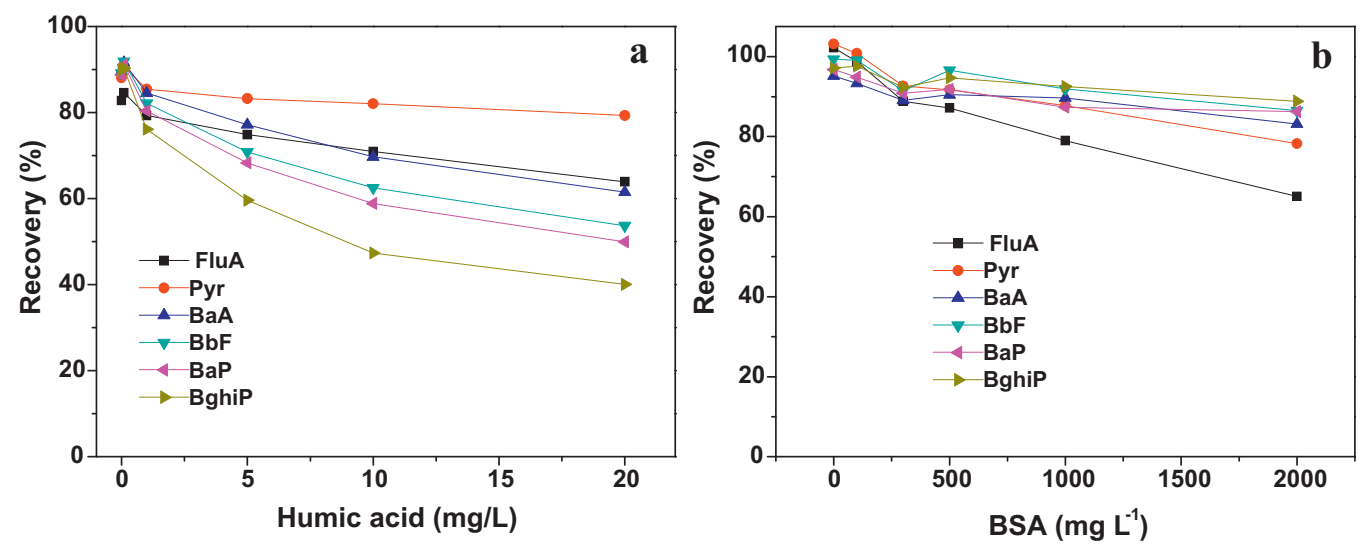

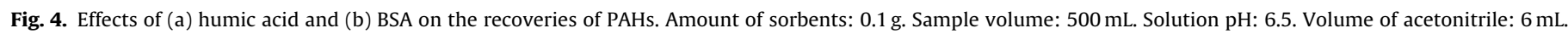
Concentration of each analyte: $50 \mathrm{ng} \mathrm{L}^{-1}$.

Table 1

Analytical parameters of the proposed method.

\begin{tabular}{|c|c|c|c|c|}
\hline Analytes & Linearity range $^{\mathrm{a}}\left(\mathrm{ng} \mathrm{L}^{-1}\right)$ & Calibration equations & Correlation coefficient $(R)$ & Detection limit ${ }^{\mathrm{b}}\left(\mathrm{ng} \mathrm{L}^{-1}\right)$ \\
\hline FluA & $1-200$ & $y=0.1522 x+1.4614$ & 0.9999 & 0.6 \\
\hline Pyr & $1-200$ & $y=0.2663 x+2.9325$ & 0.9999 & 0.4 \\
\hline $\mathrm{BaA}$ & $1-200$ & $y=0.5142 x-2.1487$ & 0.9998 & 0.2 \\
\hline $\mathrm{BbF}$ & $1-200$ & $y=0.3271 x-0.1921$ & 0.9999 & 0.5 \\
\hline $\mathrm{BaP}$ & $1-200$ & $y=0.6298 x-2.1885$ & 0.9996 & 0.2 \\
\hline BghiP & $1-200$ & $y=0.4687 x-1.2499$ & 0.9998 & 0.5 \\
\hline
\end{tabular}

a Concentration of standard solution are $1,10,50,100,200 \mathrm{ng} \mathrm{L}^{-1}$.

b Detection limits are calculated using $\mathrm{S} / \mathrm{N}=3$.

Table 2

Comparison of different magnetic nanomaterials for PAHs extraction.

\begin{tabular}{|c|c|c|c|c|}
\hline Material & Sample volume $(\mathrm{mL})$ & Detection & $\operatorname{LOD}\left(\operatorname{ng~L}^{-1}\right)$ & Reference \\
\hline Alkyl carboxylates-coated $\mathrm{Fe}_{3} \mathrm{O}_{4}$ & 350 & LC-FLD & $0.2-0.5$ & [1] \\
\hline Ionic liquid-coated $\mathrm{Fe}_{3} \mathrm{O}_{4}$ & 300 & LC-FLD & $0.33-8.33$ & {$[2]$} \\
\hline Carbon-ferromagnetic nanocomposite & 20 & GC-MS & $15-335$ & [3] \\
\hline Octadecyl functionalized magnetic microspheres & 20 & GC-MS & $800-3600$ & {$[4]$} \\
\hline Hydrophobic $\mathrm{Fe}_{3} \mathrm{O}_{4}$ retrieved 1-octanol & 20 & GC-MS & $11.7-61.4$ & [5] \\
\hline PC bilayer coated $\mathrm{Fe}_{3} \mathrm{O}_{4}$ & 500 & LC-FLD & $0.2-0.6$ & This work \\
\hline
\end{tabular}

at a signal-to-noise ratio of 3, were in the range of $0.2-0.6 \mathrm{ng} \mathrm{L}^{-1}$. Therefore, the proposed method meets the requirement of PAH quantification analysis of ultra-trace level concentrations established by U. S. EPA (3.8 $\mathrm{ng} \mathrm{L}^{-1}$ ) and those set by European Union
(2-50 $\mathrm{ng} \mathrm{L}^{-1}$ ) for surface waters [16]. LOD values and extraction parameters, obtained in our work and other different magnetic SPE methods for PAHs extraction reported in literature, are shown in Table 2 for comparison. As could be seen from Table 2, the LOD

Table 3

Recoveries of real water samples spiked with six target analytes.

\begin{tabular}{|c|c|c|c|c|c|c|c|c|c|c|c|c|c|}
\hline \multirow[t]{2}{*}{ Samples } & \multirow[t]{2}{*}{ Spiked (ng L $\left.{ }^{-1}\right)$} & \multicolumn{6}{|c|}{ Detected $\left(\mathrm{ng} \mathrm{L}^{-1}\right)^{\mathrm{a}}$} & \multicolumn{6}{|c|}{ Recovery (\%) ${ }^{\mathrm{b}}$} \\
\hline & & FluA & Pyr & $\mathrm{BaA}$ & $\mathrm{BbF}$ & $\mathrm{BaP}$ & BghiP & FluA & Pyr & $\mathrm{BaA}$ & $\mathrm{BbF}$ & $\mathrm{BaP}$ & BghiP \\
\hline \multirow[t]{4}{*}{ Skim milk } & 0.00 & $\mathrm{nd}^{\mathrm{c}}$ & nd & nd & nd & nd & nd & & & & & & \\
\hline & 1 & 0.505 & 0.613 & 0.469 & 0.497 & 0.479 & 0.455 & $50 \pm 8$ & $61 \pm 6$ & $47 \pm 8$ & $50 \pm 8$ & $48 \pm 9$ & $46 \pm 5$ \\
\hline & 10 & 5.76 & 5.45 & 6.21 & 4.51 & 6.16 & 4.32 & $58 \pm 3$ & $54 \pm 3$ & $62 \pm 3$ & $45 \pm 2$ & $62 \pm 4$ & $43 \pm 1$ \\
\hline & 100 & 54.5 & 55.9 & 53.7 & 43.0 & 58.5 & 42.4 & $54 \pm 2$ & $56 \pm 2$ & $54 \pm 2$ & $43 \pm 2$ & $58 \pm 4$ & $42 \pm 1$ \\
\hline \multirow[t]{4}{*}{ Tap water } & 0.00 & nd & 1.02 & nd & 0.889 & nd & nd & & & & & & \\
\hline & 1 & 0.889 & 2.10 & 0.945 & 1.91 & 1.01 & 1.00 & $89 \pm 5$ & $108 \pm 7$ & $94 \pm 5$ & $102 \pm 7$ & $101 \pm 2$ & $100 \pm 6$ \\
\hline & 10 & 10.2 & 10.7 & 10.2 & 10.7 & 10.4 & 10.8 & $102 \pm 3$ & $97 \pm 2$ & $102 \pm 1$ & $98 \pm 5$ & $104 \pm 3$ & $108 \pm 2$ \\
\hline & 100 & 107 & 114 & 115 & 111 & 105 & 111 & $107 \pm 1$ & $113 \pm 2$ & $115 \pm 4$ & $110 \pm 3$ & $105 \pm 3$ & $111 \pm 4$ \\
\hline \multirow[t]{3}{*}{ Sea water } & 0.00 & nd & 0.904 & nd & nd & nd & nd & & & & & & \\
\hline & 10 & 10.2 & 11.4 & 9.50 & 9.21 & 9.23 & 9.66 & $102 \pm 4$ & $104 \pm 4$ & $95.0 \pm 3$ & $92.1 \pm 4$ & $92.3 \pm 4$ & $96.6 \pm 1$ \\
\hline & 100 & 101 & 112 & 112 & 105 & 99.8 & 112 & $101 \pm 1$ & $111 \pm 2$ & $112 \pm 2$ & $105 \pm 2$ & $99.8 \pm 2$ & $112 \pm 3$ \\
\hline \multirow[t]{4}{*}{ River water } & 0.00 & nd & 1.24 & 1.45 & nd & nd & nd & & & & & & \\
\hline & 1 & 0.904 & 2.16 & 2.49 & 0.990 & 1.03 & 0.999 & $90 \pm 8$ & $92 \pm 6$ & $104 \pm 5$ & $99 \pm 6$ & $103 \pm 8$ & $100 \pm 4$ \\
\hline & 10 & 11.0 & 11.5 & 11.6 & 10.5 & 10.1 & 10.3 & $110 \pm 4$ & $102 \pm 3$ & $102 \pm 3$ & $105 \pm 6$ & $101 \pm 2$ & $103 \pm 1$ \\
\hline & 100 & 100 & 107 & 110 & 100 & 103 & 102 & $100 \pm 2$ & $105 \pm 1$ & $109 \pm 1$ & $100 \pm 2$ & $103 \pm 1$ & $102 \pm 4$ \\
\hline
\end{tabular}

a Mean of three determinations.

b Standard deviation for three determinations.

c Not detected. 

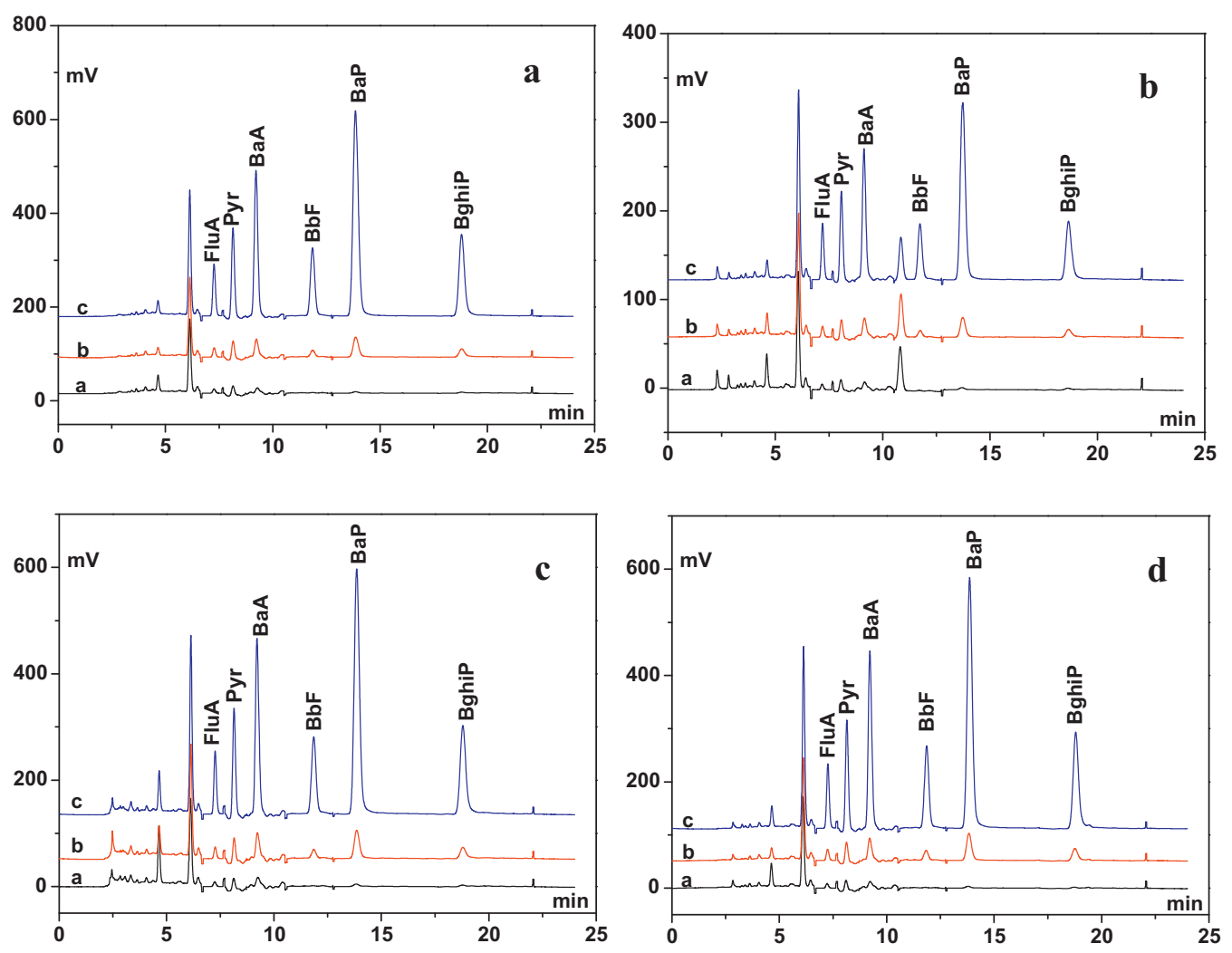

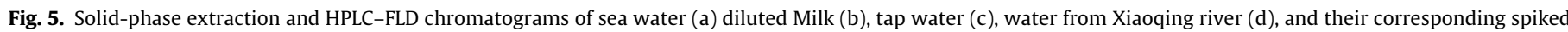
samples with $10 \mathrm{ng} \mathrm{L}^{-1}$ and $100 \mathrm{ng} \mathrm{L}^{-1}$ of each analyte. The volume of water and diluted milk sample was $500 \mathrm{~mL}$.

values of our magnetic SPE methods were relatively low compared to other methods, indicating high sensitivity of the proposed method.

\subsection{Analysis of environmental water and milk samples}

Next, we validate whether the proposed method is suitable for real sample by analyzing the concentrations of PAHs in tap water, river water, sea water and skim milk samples. The results, expressed as mean value of three independent determinations, are shown in Table 3. No analytes were detected in skim milk sample. Tap water contained $1.02 \mathrm{ng} \mathrm{L}^{-1}$ of Pyr and $0.89 \mathrm{ng} \mathrm{L}^{-1}$ of BbF. In sea water sample, $0.91 \mathrm{ng} \mathrm{L}^{-1}$ Pyr was determined. Pyr and BaA were found in river water sample, and the concentrations was 1.24 and $1.25 \mathrm{ng} \mathrm{L}^{-1}$, respectively. The concentrations of the target compounds in all the samples were at levels below the limits set by EPA and European Union. Water samples and diluted milk samples spiked with 1,10 and $100 \mathrm{ng} \mathrm{L}^{-1}$ of each analyte were determined using the overall magnetic SPE procedure. Table 3 shows concentrations, recovery and relative standard deviation (RSD) of each analyte in spiked samples. For spiked water samples, the recovery and RSD was in the range of $89-115 \%$ and $1-8 \%$, respectively, which indicated accuracy of the method. We tried to extract PAHs from milk samples spiked with analytes, and the results in supporting information showed that the recoveries were below $25 \%$, which could not meet the requirement of analysis. It was understandable that high concentration of interfering material, for example, protein and lipid-insoluble solid particles, would result in strong competition adsorption for analytes. After the milk samples were diluted from $5 \mathrm{~mL}$ to $500 \mathrm{~mL}$, RSD was satisfactory (1-9\%), and the recoveries (42-62\%) were improved compared with undiluted milk samples. The concentration of protein was low in diluted milk, and the negative effect of protein on extraction was not the key factors. To investigate whether lipids in milk result in low extraction recovery of PAHs, we applied the proposed magnetic SPE method to extract analytes from spiked pure milk (containing lipids) and skim milk (without lipids), respectively. Recoveries of analytes showed no obvious difference between pure and skim milk. So we concluded that lipids in milk had no obvious effect on extraction of PAHs, and the decrease of recovery might result from the competitive adsorption of lipid-insoluble solid particles in large quantities of milk. The $\mathrm{Fe}_{3} \mathrm{O}_{4} / \mathrm{PC}$ nanoparticle sorbents exhibited a certain potential in the application of biological sample analysis. Fig. 5(a-d) shows the chromatograms of sea water, milk, tap water, river water, and their spiked samples, in which little interference from matrix components has been observed.

\section{Conclusions}

In summary, we attach lipid bilayers on magnetic nanoparticles using a modified dry lipid film hydration method and use the obtained magnetic sorbents to extract trace PAHs from environmental water and biological samples. The advantages of the proposed method include rapid and convenient extraction operation, feasibility for large-volume sample, high sensitivity and precision, and some anti-interference to NOM and protein. Due to the hydrocarbon chains of PC providing adsorption sites through hydrophobic interaction, the sorbents can extract not only PAHs, but also other less polar organic pollutants, for example, phthalate esters, phenolic compounds, and perfluorinated compounds (support information). This work opens up new avenues for the application of phospholipids and magnetic nanoparticles in analytical chemistry. 


\section{Acknowledgements}

This work was jointly supported by National Basic Research Program of China (2009CB421605, 2011CB936001); the National Natural Science Foundation of China (20975110, 20907061, 20921063); the Natural Science Foundation of Shandong Province (ZR2010BM027, ZR2011BQ012).

\section{Appendix A. Supplementary data}

Supplementary data associated with this article can be found, in the online version, at doi:10.1016/j.chroma.2012.03.056.

\section{References}

[1] X. Zhao, Y. Shi, T. Wang, Y. Cai, G. Jiang, J. Chromatogr. A 1188 (2008) 140

[2] X. Zhao, Y. Shi, Y. Cai, S. Mou, Environ. Sci. Technol. 42 (2008) 1201.

[3] X. Zhao, Y. Cai, T. Wang, Y. Shi, G. Jiang, Anal. Chem. 80 (2008) 9091

[4] J. Li, X. Zhao, Y. Shi, Y. Cai, S. Mou, G. Jiang, J. Chromatogr. A 1180 (2008) 24

[5] S. Zhang, H. Niu, Z. Hu, Y. Cai, Y. Shi, J. Chromatogr. A 1217 (2010) 4757

[6] S. Zhang, H. Niu, Y. Cai, Y. Shi, Anal. Chim. Acta 665 (2010) 167.

[7] H.-H. Yang, S.-Q. Zhang, X.-L. Chen, Z.-X. Zhuang, J.-G. Xu, X.-R. Wang, Anal. Chem. 76 (2004) 1316

[8] L. Sun, C. Zhang, L. Chen, J. Liu, H. Jin, H. Xu, L. Ding, Anal. Chim. Acta 638 (2009) 162

[9] Y. Song, S. Zhao, P. Tchounwou, Y.-M. Liu, J. Chromatogr. A 1166 (2007) 79.

[10] Y. Liu, L. Jia, Microchem. J. 89 (2008) 72.

[11] H.-H. Hsiao, H.-Y. Hsieh, C.-C. Chou, S.-Y. Lin, A.H.J. Wang, K.-H. Khoo, J. Proteome Res. 6 (2007) 1313.

[12] L. Chen, J. Liu, Q. Zeng, H. Wang, A. Yu, H. Zhang, L. Ding, J. Chromatogr. A 1216 (2009) 3710.

[13] C.-T. Chen, Y.-C. Chen, Anal. Chem. 77 (2005) 5912.

[14] I.J. Bruce, T. Sen, Langmuir 21 (2005) 7029.

[15] F. Bao, J.-L. Yao, R.-A. Gu, Langmuir 25 (2009) 10782.

[16] A. Ballesteros-Gómez, S. Rubio, Anal. Chem. 81 (2009) 9012.
[17] Q.L. Zhang, F. Yang, F. Tang, K. Zeng, K.K. Wu, Q.Y. Cai, S.Z. Yao, Analyst 135 (2010) 2426.

[18] L. Bai, B. Mei, Q.Z. Guo, Z.G. Shi, Y.Q. Feng, J. Chromatogr. A 1217 (2010) 7331.

[19] Y. Liu, H.F. Li, J.M. Lin, Talanta 77 (2009) 1037.

[20] Z.G. Shi, H.K. Lee, Anal. Chem. 82 (2010) 1540.

[21] C.D. Calvano, O.N.Jensen, C.G. Zambonin, Anal. Bioanal. Chem. 394 (2009) 1453.

[22] R.P. Richter, R. Bérat, A.R. Brisson, Langmuir 22 (2006) 3497.

[23] I. Zawisza, X. Bin, J. Lipkowski, Langmuir 23 (2007) 5180.

[24] N.-J. Cho, S.-J. Cho, K.H. Cheong, J.S. Glenn, C.W. Frank, J. Am. Chem. Soc. 129 (2007) 10050.

[25] A. Diguet, M. Le Berre, Y. Chen, D. Baigl, Small 5 (2009) 1661

[26] K.S. Phillips, S. Kottegoda, K.M. Kang, C.E. Sims, N.L. Allbritton, Anal. Chem. 80 (2008) 9756.

[27] S. Savarala, S. Ahmed, M.A. Ilies, S.L. Wunder, Langmuir 26 (2010) 12081

[28] C. Jiang, A. Gamarnik, C.P. Tripp, J. Phys. Chem. B 109 (2005) 4539.

[29] H. Takahashi, Y. Niidome, T. Niidome, K. Kaneko, H. Kawasaki, S. Yamada, Langmuir 22 (2006) 2.

[30] M.A. Daza Millone, M.E. Vela, R.C. Salvarezza, T.B. Creczynski-Pasa, N.G. Tognalli, A. Fainstein, ChemPhysChem 10 (2009) 1927.

[31] C.J. Orendorff, T.M. Alam, D.Y. Sasaki, B.C. Bunker, J.A. Voigt, ACS Nano 3 (2009) 971.

[32] P. He, M.W. Urban, Biomacromolecules 6 (2005) 1224.

[33] B. Yuan, L.-L. Xing, Y.-D. Zhang, Y. Lu, Z.-H. Mai, M. Li, J. Am. Chem. Soc. 129 (2007) 11332.

[34] M. Gonzales, K. Krishnan, J. Magn. Magn. Mater. 293 (2005) 265.

[35] M.M. Elmi, M.N. Sarbolouki, Int. J. Pharm. 215 (2001) 45.

[36] J. Giri, S. Guhathakurta, J. Bellare, A. Kumarnigam, D. Bahadur, J. Magn. Magn. Mater. 293 (2005) 62

[37] F.M. Rocha, S.C. de Pinho, R.L. Zollner, M.H.A. Santana, J. Magn. Magn. Mater. 225 (2001) 101.

[38] E.T. Castellana, R.C. Gamez, D.H. Russell, J. Am. Chem. Soc. 133 (2011) 4182.

[39] Y.S. Kang, S. Risbud, J.F. Rabolt, P. Stroeve, Chem. Mater. 8 (1996) 2209

[40] S.-F. Lim, Y.-M. Zheng, S.-W. Zou, J.P. Chen, Environ. Sci. Technol. 42 (2008) 2551.

[41] M. Hennion, J. Chromatogr. A 885 (2000) 73.

[42] N. Li, H. Lee, Anal. Chem. 72 (2000) 5272.

[43] N. Li, H. Lee, J. Chromatogr. A 921 (2001) 255.

[44] D. Hinckley, T. Bidleman, Environ. Sci. Technol. 23 (1989) 995.

[45] W. Johnson, N. Fendinger, J. Plimmer, Anal. Chem. 63 (1991) 1510. 